\title{
Questions for Dr Victoria Harmer - Imperial College Healthcare NHS Trust: a look into cancer nursing
}

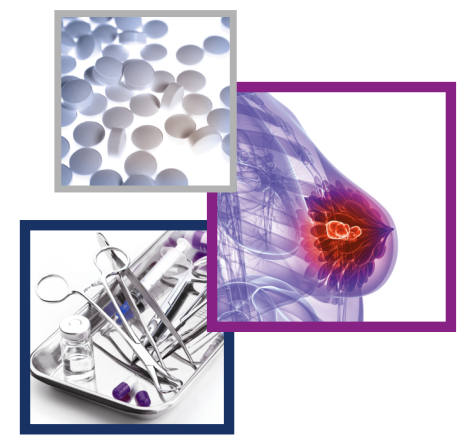

\author{
Victoria Harmer*,1 \\ ${ }^{1}$ Breast Services Unit, Imperial College Healthcare NHS Trust, Charing Cross Hospital, Fulham Palace Road, London W6 8RF, UK \\ * Author for correspondence: victoria.harmer@nhs.net
}

'I have been very lucky with all the opportunities that have come my way."

Dr Victoria Harmer speaks to Roshaine Wijayatunga, Senior Editor: Oncology. Victoria Harmer is a Macmillan Consultant Nurse (breast) at Imperial College Healthcare NHS Trust. She manages nine nurse specialists and is heavily involved in service delivery and improvement for both the screening and symptomatic services. She has published over 70 articles for nursing and medical journals, as well as editing the book "Breast Cancer Nursing Care and Management". In addition, she has written several chapters in books and acted as medical adviser for radio, television and film. In 2013, she was awarded the Nursing Times Cancer Nursing award which represents excellence in nursing and patient care. Dr Harmer has a degree in nursing from Kings College, an MBA from Westminster Business School, a doctorate from Kings and is also an Associateship of Kings College.

First draft submitted: 7 April 2017; Accepted for publication: 7 April 2017; Published online: 2 February 2018

\section{How did you make the decision to pursue a career as a nurse \& how did this lead to you} becoming a Consultant Nurse?

Well, I sort of fell into nursing to be honest. I always wanted to be a marine biologist or a geologist but then it was suggested I should try nursing. I was not sure about it at all, but nevertheless I became a healthcare assistant and absolutely loved it! I loved the team I was working with, loved working as part of a team and I also liked the unusual hours - I thought that was quite fun.

I still remember my experience of being a healthcare assistant now. It was during this time that I really understood, the importance of disseminating knowledge - through bedside teaching, and more formalized programs of course. It makes the person receiving the knowledge feel more nurtured, supported and valued which can only translate to an increase in the quality of patient care delivered and better team morale. I also understood what an important job the healthcare assistants perform and what differences they make.

I qualified with an award for distinction in practice and went straight into oncology. I worked on an oncology ward for a year and then went into the surgical side; at the time breast and bowel surgery were grouped together on the same ward, and I worked in this area for a number of years at the Middlesex and University College Hospital which I enjoyed greatly. Following that, I thought I had sharpen up my skill set so worked in the intensive care unit for 6 months before becoming a Sister of the surgical oncology ward at St Mary's.

In 1995/1996, when I did my degree in nursing studies, the dissertation was on 'Women's perceptions and experience of radiotherapy for early stage cancer' - so even early on, there was always that thread of breast cancer. After I had been on the ward for a while, the specialist nurse for cancer went on maternity leave, so I applied for the post.

I have been very lucky with all the opportunities that have come my way. Practically immediately (in 2000), researchers from the BBC Radio 4 program 'The Archers' contacted me to help with writing the scripts and ensuring medical content in them were correct. Having done that, I wanted to keep pushing things along so wrote to 'Nursing Times' magazine and asked them if I could submit a piece for their 'Letters' page. I thought the process of working with radio and the researchers was quite interesting and that credit should be given as they wanted the 
storylines to be robust. 'Nursing Times' did publish my piece moreover they asked me if I would be interested in writing a series of articles on cancer. I took that opportunity, and as I was relatively new to the post of nurse specialist found it a good way to learn; researching a subject and then basically writing an essay on it for publication.

On the back of that series, I was approached by another publisher asking if I would write or edit a textbook on cancer. I took this opportunity as well and now the book is in its second edition; Prince Charles has written the book's foreword and Stella McCartney some words of encouragement. Actually, I have just agreed to edit another book on cancer nursing which is my next project and finds me sourcing appropriate authors.

I have been to Marks and Spencer to assist in designing swimwear for the postmastectomy body, I am a Trustee for Against Cancer charity, I helped with other cancer storylines (in addition to 'The Archers') such as Chanel 5's 'Family Affairs', ITV's 'Coronation Street' and BBC1's 'EastEnders', when I worked on a number of storylines including the death of Peggy Mitchell (played by Dame Barbara Windsor). I was absolutely humbled to get positive feedback from Dame Barbara Windsor as below:

\section{"Having a qualified cancer nurse on set such as Vickki has been a great sense of comfort to me as an actress, approaching such a serious and sensitive health matter is very daunting as you wish to get things right as a mark of respect for the people are affected by this awful illness." \\ "I think it's imperative that TV, film and theater companies continue to seek professional advice and work alongside such people and organizations when dealing with health matters. I will be eternally grateful to Vickki for her guidance" Dame Barbara Windsor (2016).}

These media opportunities are great but certainly a commitment as they start with discussions with the researchers, then reading and commenting on scripts - timelines, language used and appropriateness of treatment/accuracy of storylines and then the visits on-set to advise during filming the scenes. Additionally, I worked on a film with Toni Collette - 'Miss You Already' and also a day at Pinewood with Kevin Costner (on his film 'Criminal') which was exciting. The most recent television work was a day on the BBC2 comedy 'Fleabag'.

Apart from this I have written about 70 articles for nursing press, a few chapters for books and completed an MBA. I was invited to give a keynote address at a conference in Australia, have done some work teaching nurses in the Gulf in Dubai and other work lecturing in Antwerp, New York, Lisbon and Paris and assisting in writing National Guidelines among others... The best part of all though is the fabulous, kind and gifted team I work with in the services department at Imperial College Healthcare Trust.

\section{You won 'Nursing Times' cancer nursing award in 2013: congratulations! How important is it in your experience to always put the patient first?}

It is absolutely imperative - it is the reason we are here. The patient is the expert of themselves and they should be the focus of everything. I think that is why that Cancer Nursing award was absolutely one of my highlights, because I was nominated by patients. After being shortlisted, I had to go and give a presentation and took a couple of the patients with me. The awards night was in Park Lane - and again I invited a couple of patients; it was such a fantastic event which represents true excellence in nursing and patient care during an evening of recognition and celebration. Keeping the patient completely at the center of what you do is so important. I think the hardest thing at the moment is trying to work smarter and do more with less resource, while still trying to maintain a quality of service and meet patient expectations. Quite rightly, patients expect more as we go along, certainly with reconstruction, and so it is trying to match that expectation with the service - building the organization around the patient as opposed to the patient around the organization.

\section{Can you tell us a bit about the Pan-London Nurse Specialist Forum \& what your specific role is?}

This has been going on in one guise or other for many years; formally it was the meeting of the nurses from the London Cancer Alliance (now defunct) and the West London Cancer Network (before that). Essentially we invite all the specialist nurses in London to a meeting which we hold quarterly. We include specialist nurses from NHS and Private hospitals and in addition, usually have representatives from Cancer Care and the Cancer Haven. During these meetings we discuss a specific topic - I believe the last one was 'Getting back to normal'. We also talk over any issues or problems people share and try to find a solution; benchmarking across London. We can identify what information people are using and also how people are developing their services. There is also a section on feedback from study days and an update from the NHS screening service. Since the meetings are sponsored by pharma, 
there is also an educational session when we get an update from that company on their cancer treatment. There is supper supplied at the end of the meeting and this informal get-together is really key - a lot of support/networking happens, which is vital for your emotional resilience and to stop burnout, not to mention it makes a fun part to the meeting as well!

\section{Do you think oncology nurses have enough support \& training currently?}

Leadership in nursing is vital in order nurses feel supported during these times when we are under relentless pressure. The importance of team bonding/team building and nurturing staff should not be underestimated. Times are tough and this should be acknowledged and staff encouraged and praised.

Training budgets have been culled dramatically, so nurses are less able to attend formal courses and modules, so it is important to go back to basics with teaching colleagues in the work place. The most important thing in my mind is the transference of knowledge from the classroom to the bedside and clinical environment. I do not think it is about nurses attending course after course after course; what does make sense is that partnered with experience and reflection while auditing patient care and acting on results. Anyone can attend a course, but the gift is to translate it to the work place in order the quality of care be increased. I do think that if you invest time teaching nurses (be it in the classroom or more informally), then they will feel nurtured and encouraged; invested in which will make a happier workforce - and a happier workforce makes for a happier patient.

\section{One aspect of your work is making school visits to speak about this topic. Why do you think it is important to educate people about cancer $\&$ what kind of topics do you highlight in your sessions?}

So here, we speak to the mothers who drop their children off at school. I have done a lot traditionally for cancer awareness month - for example, I have had stands at Paddington Station and gone to Wormwood Scrubs to talk to the prison wardens so they can disseminate the information. We have done a lot of work with people with learning disabilities, because they of course, are a vulnerable group and evidence shows they do not turn up for screening. I have worked for a number of years with learning disability organizations, and found a visual of a false helpful in order to show what to look out for. We have also invited people with learning disabilities to the screening units at Imperial to try and demystify the procedures by showing them the machinery and also the healthcare professionals who would perform the mammograms. We also ensured we had drinks and the customary pink cakes!

We worked with the local tri-boroughs last year through Yarrow Housing when we participated in a 'Bingo and Awareness' event, during which I gave a little talk on being aware and what to look for before we got down to bingo - the event was successful and we got coverage in local press and even on the ITV 6 pm news.

I have also been to Harrods head office, which is just local to where I work, and had a stand in the staff canteen, once more with a false with lumps in it, talking about what to look for.

We contact local businesses prior to cancer awareness month (October) and see if they wish for someone to give a talk to their team. This reflects well on the hospital, raising it's profile and also promotes breast awareness. After all, we do have the wonderful vehicle of cancer awareness month, so would be a shame not to use it.

\section{You recently presented at the 4th Association of Surgery Multidisciplinary Meeting on the topic, 'Radiotherapy postimmediate DIEP flap reconstruction. The patient's perspective'. Do you think patients get enough advice $\&$ information regarding their treatment \& options available to them?}

There is such a wealth of information for patients. There are masses of resources that we have, especially within cancer and care. There are certainly pivotal points in a patient's cancer journey when decision making is vital and you should also factor in that the patient may have been recently diagnosed with this potentially life threatening disease; thus, they are vulnerable and in crisis. I kind of went into this study thinking, "Gosh this type of reconstruction is such a huge operation, and I am not sure they know exactly what they are in for!" You could say it was sort of paternalistic of me - I was really quite protective. But in my experience, the patients are such a feisty and resilient bunch - it is absolutely wonderful to see. 
Why did you decide to conduct a study to investigate women's perspectives of radiotherapy combined with DIEP free flap reconstructions postmastectomy for cancer? (i.e., what was the background for the study \& study objectives?)

I did the study because there seemed to be a bit of disparity about what women would be offered throughout the UK and we know that NICE recommendations propose (as long as there are no significant comorbidities) that everyone should be invited to have a reconstruction at the same time as a mastectomy if they would like, but we know from the NHS National Mastectomy and Reconstruction audit that only about 21\% take it up. Now we have looked at our figures again and we think that it is probably about $40-50 \%$ but at the time of operation we do not know for sure whether radiotherapy will be recommended as an adjuvant treatment. You can hazard a guess, but you do not absolutely know for definite. So some units would not offer a woman a reconstruction if they thought that postoperative radiotherapy would be needed because they think it would have a detrimental effect on the reconstruction. There is disparity about what women were being offered, or not, and when I looked at the evidence regarding radiotherapy postautologous reconstruction, I found that it was quite flimsy. The evidence was contradictory and data were pooled - some articles grouped together the women who had had implant reconstruction as well as those who had tissue only and the data were mainly from the clinician's point of view or what the clinician thinks about the results of the postoperative radiotherapy. Well, while it is obviously important to understand the clinicians thoughts about the potential consequences of that combination of treatment, what really matters is what the patient thinks about it as they are the ones living through potential consequences.

Furthermore, all of the outcome measures were all mixed up. Re-operation rates or postoperative complications, for example, in many articles were talking about cosmetic things - like a nipple reconstruction, and of course that does not ring true. So this research was the first qualitative study illustrating the women's perspective of radiotherapy combined with a deep inferior epigastric perforator flap immediate reconstructions postmastectomy for cancer.

\section{Can you tell our readers a little about the study design?}

It was a qualitative study, with 14 women and I held three separate focus groups. It was externally facilitated by an expert in focus groups who is a Professor of Nursing. I used the framework method for analysis and that involved seven steps to identify themes. You end up with huge reams of unwieldy (being qualitative, you can imagine!) and so you need to work through these seven steps to allow flexibility and to move between the levels of interpretation without losing sight of the raw data. I obviously got ethics approval and I had supervision from Kings College which is where I did the doctorate.

Clearly I thought about what to ask the focus group. I looked at the literature and I pulled together some guide domains to drive the conversation; these all were in relation to adjuvant radiotherapy postautologous tissue reconstruction. I then refined these domains and used co-design, through an 'expert panel' made up of 11 clinicians I work with (plastic surgeons, surgeons, oncologists and nurses), and also a 'user panel' made up of 13 patients. I asked both panels to review the questions and asked their opinions of them.

\section{How would you summarize your study overall \& what are the next steps?}

I would underline that although it matters what healthcare professionals think, it really matters what the women who are living with the potential consequences of this combination of treatment think. Personally, I feel that it is really refreshing to hear what these particular women think. It is the first qualitative report and it is not generalizable, it is just what those women meant at that time, but it is, I think very powerful. There was a huge amount of data, and when going through the data, you gain the realization of how feisty these women are and actually what the body can put up with. It was such a privilege speaking to the women and realizing their resilience. People do not just crumble, they do adapt to the 'new normal' - normalization and they recalibrate.

Interestingly enough, coincidentally, the plastic teams here at the Trust have started doing a different upfront information-giving session for patients which as I said was one of the things that I identified in my study. They are going to audit the practice. I am obviously going to write the study up for a number of different forums including journals and nursing magazines.

\section{What other projects are you working on?}

We are already working on service improvement things at the moment. I am the nurse representative of the OPTIMA trial management group - that is a great study. I am also hopefully going to be a steering advisory group 
member for a study looking at partners coping with a spouse with increased risk of developing hereditary cancer. As a Consultant Nurse, research is very much in the thread - there is much we have to do in the clinical environment.

\section{How would you like to see cancer nursing change in the next 5-10 years?}

Well I think we have got to be cleverer and I think we have got to try and straddle the community a little better, as care is becoming more ambulatory, moreover many of the new targeted treatments are oral and thus being taken while the patient is at home. And again, thinking of how we can dovetail the support needs of the patient and resources, because it is all very well us coming up with new pathways, but we need to make sure that we factor in the support. Also we need to look at support for the caregivers - because caregivers are so important and we are asking them to do more and more. I think we also need to focus more on the nursing workforce and the nurse specialists. The market place is a little scanty at the moment, so we are almost trying to grow our own and do some developmental posts to keep people interested and generate some enthusiasm.

It is quite tough and I think that certainly if I am looking for people up and coming to write a chapter in my book, there are not that many youngsters. How can we encourage/think of different ways of resolving this?

\section{Do you have any closing remarks for our readers?}

I think you need to be armed with tenacity to work in the NHS at present as there is relentless pressure and you are asked to continually do more with the same or less. That being the case, the research I undertook concentrated wholly on the patient which should be the focus of all that we do. It was such a privilege to speak to the participants and I felt humbled that they felt so open to discuss such an intense time of their lives. The research has given me more insight both as a person and a healthcare professional, and I realize how privileged I was to have had access to these women.

\section{Disclaimer}

The opinions expressed in this interview are those of the interviewee and do not necessarily reflect the views of Future Medicine Ltd.

\section{Financial \& competing interests disclosure}

The author has no relevant affiliations or financial involvement with any organization or entity with a financial interest in or financial conflict with the subject matter or materials discussed in the manuscript. This includes employment, consultancies, honoraria, stock ownership or options, expert testimony, grants or patents received or pending, or royalties.

No writing assistance was utilized in the production of this manuscript. 